\title{
Effectiveness and safety of glucosamine and chondroitin for the treatment of osteoarthritis: a meta-analysis of randomized controlled trials
}

\author{
Xiaoyue Zhu', Lingli Sang ${ }^{2}$, Dandong $\mathrm{Wu}^{2}$, Jiesheng Rong ${ }^{3}$ and Liying Jiang ${ }^{4^{*}}$
}

\begin{abstract}
Objective: To assess the symptomatic effectiveness and safety of oral symptomatic slow-acting drugs (SYSADOAs) on the treatment of knee and/or hip osteoarthritis, such as chondroitin, glucosamine, and combination treatment with chondroitin plus glucosamine.

Methods: We searched electronic database including PubMed, Embase, Cochrane Library, and the reference lists of relevant articles published from inception to May 22, 2018. An updated meta-analysis was performed to assess the effectiveness of these slow-acting drugs for osteoarthritis.

Results: Twenty-six articles describing 30 trials met our inclusion criteria and were included in the meta-analysis. The estimates between chondroitin and placebo showed that chondroitin could alleviate pain symptoms and improve function. Compared with placebo, glucosamine proved significant effect only on stiffness improvement. However, the combination therapy did not have enough evidence to be superior to placebo. Additionally, there was no significant difference in the incidence of AEs and discontinuations of AEs when compared with placebo.

Conclusions: Given the effectiveness of these symptomatic slow-acting drugs, oral chondroitin is more effective than placebo on relieving pain and improving physical function. Glucosamine showed effect on stiffness outcome. Regarding on the limited number of combination therapy, further studies need to investigate the accurate effectiveness. This information accompanied with the tolerability and economic costs of included treatments would be conducive to making decisions for clinicians.
\end{abstract}

Keywords: Osteoarthritis, Glucosamine, Chondroitin, Treatment

\section{Background}

Osteoarthritis (OA), characterized by progressive cartilage matrix degradation, subchondral bone sclerosis, and osteophyte formation, is the most common form of arthritis $[1,2]$. Globally, the prevalence of OA, particularly of the large weight-bearing joints such as the knee and hip, is also predicted to grow [3]. Presently, OA has emerged as one of the major public health concerns and continues to affect about $10 \%$ of men and $18 \%$ of women over 60 years of age [1].

\footnotetext{
* Correspondence: J_meili@126.com

${ }^{4}$ Shanghai Key Laboratory for Molecular Imaging, Shanghai University of Medicine \& Health Sciences, Shanghai, People's Republic of China Full list of author information is available at the end of the article
}

Previous studies suggest that aging, genetic predisposition, obesity, inflammation, and excessive mechanical loading predispose to OA occurrence and development [4]. The structural changes result in joint pain and stiffness, swelling, and tenderness, which can eventually lead to disability and affect the quality of life of patients [5]. Treatment strategies of OA include both non-pharmacological and pharmacological therapies. Among pharmacological therapies, analgesics and non-steroidal anti-inflammatory drugs (NSAIDs) are current treatment options for OA because of their well-established effectiveness. However, they act as symptomatic treatments without offering disease modification of $\mathrm{OA}$, and they are accused for increased risk adverse events, including the gastrointestinal and/or cardiovascular system

(c) The Author(s). 2018 Open Access This article is distributed under the terms of the Creative Commons Attribution 4.0 International License (http://creativecommons.org/licenses/by/4.0/), which permits unrestricted use, distribution, and 
[6]. For this reason, attention has recently been focused on an ideal treatment, which can improve the clinical symptoms of OA with better tolerability and safety profiles, such as symptomatic slow-acting drugs (SYSADOAs) [7].

Glucosamine and chondroitin, as important medicine in those SYSADOA, are naturally occurring compounds in the body functioning as the principal substrates in the biosynthesis of proteoglycan [8, 9]. It is suggested that glucosamine and chondroitin are both partially absorbed and then reaches the joints, exerting on relieving joint pain and slowing the rate of joint destruction and cartilage loss. They are two main categories of agents potentially or theoretically acting as chondroprotective agents and disease-modifying OA drugs (DMOADs) [8, 10]. The effectiveness based on the result of RCT published in 2013 suggested that consumption of chondroitin for certain dosage has a positive effect on pain relief and function improvement [7]. Recently, a trial conducted in 2017 demonstrated a lack of superiority of chondroitin and glucosamine combination therapy over placebo [11]. Although many studies have shown a significant treatment effect, accompanied with remarkable safety, there is still controversy regarding the effectiveness of these putative DMOADs compared with placebo $[7,11]$. International guidelines for the management of OA had given an equivocal recommendation of glucosamine and chondroitin, and they are not recommended according to Osteoarthritis Research Society International (OARSI) guidelines published in 2014 [12].

Therefore, based on existing evidence, a study needs to be updated and critically evaluates the current evidence-based information about the administration of glucosamine and chondroitin for the treatment of knee or hip OA. In our study, a relatively comprehensive meta-analysis was performed to assess the effectiveness and safety of putative DMOADs.

\section{Methods}

\section{Search strategy}

We conducted this meta-analysis following the PRISMA extension statement [13]. We systematically searched electronic database including PubMed, Embase, and Cochrane Library based on logic combination of keywords and text words associated with OA to extract concerned RCTs from inception to May 22, 2018. The Internet-based search used the following terms: "arthritis," "osteoarthritis," "OA," "joint disease," "glucosamine," "GH," "GS," "chondroitin," "CH," "CS," and the corresponding free terms. The search was restricted to English language and studies of human participants. We then screened reference lists of all obtained articles, including relevant reviews, to avoid missing relevant articles. And, we also searched ClinicalTrials.gov for progressive trials.

\section{Inclusion and exclusion criteria}

Studies were included if they met the following criteria: (1) RCTs; (2) studies about primary hip and/or knee OA patients with clinical and/or radiologic diagnosis; (3) studies covering at least two of the following oral treatments: glucosamine, chondroitin, or the two in combination against placebo; and (4) extractable data reporting the pain, function, stiffness, and the adverse events (AEs) of patients.

The exclusion criteria were as follows: (1) studies of non-randomized and/or uncontrolled trials, (2) treatment methods described unclearly, (3) interventions combined with non-steroidal anti-inflammatory drugs, (4) studies or data reported repeatedly, and (5) trial arms with sub-therapeutic doses $(<1500 \mathrm{mg} /$ day of glucosamine and $<800 \mathrm{mg} /$ day of chondroitin (according to dosage licensed in Europe)) [14].

\section{Data extraction}

Two investigators (X.Y.Z and L.L.S) independently assessed all studies for eligibility and extracted data in accordance with a preconfigured form from each study. Any disagreements were resolved through discussion with a third reviewer (L.Y.J). For each study, patients' characteristics including mean age, sex, mean duration of symptom, BMI, duration of follow-up, type of outcome (pain, function, stiffness, and AEs), trial design, trial size, details of intervention, treatment duration, and results were individually extracted. Data of intention-to-treat analysis was employed whenever possible.

\section{Quality assessment}

The Cochrane Risk of Bias Tool was used to evaluate the methodological quality of the included studies (version 5.3) [15]. The tool evaluated seven potential risks of bias: random sequence generation, allocation concealment, blinding of participants, blinding of outcome assessment, incomplete outcome data, selective reporting, and other bias. Each item was judged by the following criteria: low risk of bias, uncertain risk of bias, and high risk of bias. Whenever studies included three or more high risk of bias, it was considered as poor methodological quality. Two reviewers (X.Y.Z and L.L.S) checked the profile of each included study independently.

\section{Outcome measures}

The primary outcomes of this meta-analysis were pain intensity, function improvement, and stiffness score from baseline to the end of treatment. The secondary outcome was safety of studies. We preferred to the scale that was recognized to be the highest on the hierarchy of those suggested outcomes when more than one pain scales were given for a trial. Among these scales, global pain has precedence over pain on walking and the Western Ontario and McMaster Universities Osteoarthritis Index (WOMAC) pain subscale [16, 17]. 
Similarly, the data of function and stiffness was extracted with the same method. If global function score was not reported, the walking disability, function subscale of WOMAC, or Lequesne Index would be applied instead.

The standard mean difference (SMD) was used to calculate the difference between two interventions because different studies assessed the same outcome by employing different scales. SMD expresses the size of the intervention effect in each study relative to the variability observed in that study by dividing the pooled SD of the differences between two interventions [18, 19]. The effect size was transformed back to the different units of the WOMAC Visual Analogue Scale (VAS), the most commonly used scale based on a media pooled SD of $2.5 \mathrm{~cm}$ to assess pain on the scale of 0 to $10 \mathrm{~cm}$. A standardized WOMAC function score $(0-10)$ was transformed by SMD, which based on a median pooled SD of 2.1 units. A change of 2 points on the $0-10$ scale was interpreted clinically significant improvement [20]. The negative effect size indicated a better treatment effect on pain relief and function improvement.

\section{Statistical analysis}

All results summarized using STATA software (version 13.1, StataCorp, College Station, TX). For continuous outcomes, SMD with $95 \%$ credible interval $(\mathrm{CI})$ was used to present the effect size. For counting data, we calculated relative risk (RR) with $95 \% \mathrm{CI}$. The heterogeneity between studies was tested using the $Q$ statistics. $P<0.1$ was considered statistically significant. And, $I^{2}$ was used to quantify the inconsistency among the potentially disparate sources of studies. A random-effects model was used if $I^{2}>50 \%$. A subgroup analysis was conducted because there were different types of SYSADOA. Publication bias was examined through visual inspection of funnel plot asymmetry. A sensitivity analysis was performed to evaluate the effect of each study on the combined effect size by omitting each study.

\section{Results}

\section{Study selection and characteristics}

A flowchart of study search and selection was presented in Additional file 1: Figure S1. We identified 1407 references in our literature search and out of 97 potentially eligible studies, 26 articles describing 30 trials met our inclusion criteria and were included in the meta-analysis $[7,11,21-44]$. All trials were published as full journal articles and all trials used a placebo control. Only two articles compared the effectiveness among glucosamine, chondroitin, and the two in combination with placebo at one time $[29,33]$. Therefore, 14 RCTs were employed to assess the effectiveness of oral glucosamine, 12 studies were included in the analysis of oral chondroitin, and 4 trials were used to estimate the effectiveness in the subgroup of the combination of glucosamine and chondroitin. Characteristics of included studies were shown in Table 1. All of these included studies were published in English language. A total of 7172 participants were enrolled in this meta-analysis for the pain outcome. Most trials included patients with only knee OA, 1 trial [42] included patients with knee or the hip OA, and 1 trial [31] included patients with the only hip OA. The average age of the patients ranged between 42.65 and 67.09 years (median, 62.28 years), and the percentage of women ranged from 28 to $93 \%$ (median, 65\%). The average duration of symptoms was reported in 14 trials $[11,21-25,27-32,41,42]$ and ranged from 1.60 years to 12.98 years (median, 8.05 years).

\section{Risk of bias}

Risk of bias in those included studies was summarized in Additional file 1: Figure S2. All studies were judged as low risk of bias for blinding to patients. Randomization was mentioned in all trails. Nevertheless, $6 \%$ did not report details of adequate sequence generation. All studies were judged as low risk of bias for blinding for patients, while $65 \%$ for blinding to outcome assessment. In addition, 15\% trails did not describe the method of allocation concealment and $92 \%$ reported complete outcome data. None of the studies was thought to have poor methodological quality.

\section{Pain}

All studies (7127 patients) contributed to the meta-analysis of pain-related outcomes for the putative DMOADs compared with placebo (Table 1). Fourteen trials (2845 randomized patients) compared glucosamine with placebo [21-34]. Twelve trials (3082 randomized patients) compared chondroitin with placebo [7, 29, 33, 35-43]. Four trials (1200 randomized patients) compared the two in combination with placebo [11, 29, 33, 44].

The meta-analysis identified an overall effect size of -0.071 (95\% CI, -0.228 to 0.085$)$. When the SMD was transformed, glucosamine showed no significant effect compared with placebo (effect size, $-0.263 \mathrm{~cm}$ [ $95 \% \mathrm{CI},-0.635$ to $0.113 \mathrm{~cm}]$ ). However, chondroitin showed better effect compared with placebo (effect size, $-0.540 \mathrm{~cm}[95 \% \mathrm{CI},-0.900$ to $-0.178 \mathrm{~cm}]$ ). Glucosamine plus chondroitin presented no significant effect when compared with placebo (effect size, $1.980 \mathrm{~cm}$ [95\% CI, -0.740 to $4.700 \mathrm{~cm}$ ]) (Table 2). A funnel plot based on studies on the effect size was generated to detect the potential publication bias, and it manifested a significant asymmetry in Additional file 1: Figure S3.

\section{Function}

Twenty-five trials (6667 patients) contributed to the meta-analysis of physical function. Table 2 showed estimates across different treatments compared with placebo. 
Table 1 Characteristics of the included studies for osteoarthritis of knee and/or hip

\begin{tabular}{|c|c|c|c|c|c|c|c|c|c|c|}
\hline Study, year & $\begin{array}{l}\text { Treatment } \\
\text { (daily dose) }\end{array}$ & $\begin{array}{l}\text { Participants } \\
\text { randomized }(n)\end{array}$ & $\begin{array}{l}\text { Treatment } \\
\text { duration } \\
\text { (weeks) }\end{array}$ & $\begin{array}{l}\text { Symptom } \\
\text { duration (year) }\end{array}$ & $\begin{array}{l}\text { Mean } \\
\text { age (year) }\end{array}$ & $\begin{array}{l}\text { Female } \\
(\%)\end{array}$ & $\begin{array}{l}\text { OA } \\
\text { grade }\end{array}$ & Joint & $\begin{array}{l}\text { Pain outcome } \\
\text { extracted }\end{array}$ & $\begin{array}{l}\text { Timepoint } \\
\text { extracted } \\
\text { (weeks) }\end{array}$ \\
\hline \multicolumn{11}{|c|}{ Glucosamine vs placebo } \\
\hline $\begin{array}{l}\text { Noack } \\
1994[21]\end{array}$ & $\begin{array}{l}\mathrm{G}(1500 \mathrm{mg}) / \\
\text { placebo }\end{array}$ & $126 / 126$ & $1-4$ & $2.00-10.00$ & 55.00 & 60 & $|-|||$ & Knee & $\begin{array}{l}\text { Lequesne global } \\
\text { scale }\end{array}$ & 4 \\
\hline $\begin{array}{l}\text { Houpt } \\
1999 \text { [22] }\end{array}$ & $\begin{array}{l}\mathrm{G}(1500 \mathrm{mg}) / \\
\text { placebo }\end{array}$ & $58 / 60$ & $1-8$ & 8.30 & 64.46 & 62 & NA & Knee & WOMAC & 12 \\
\hline $\begin{array}{l}\text { Reginster } \\
2001[23]\end{array}$ & $\begin{array}{l}\mathrm{G}(1500 \mathrm{mg}) / \\
\text { placebo }\end{array}$ & $106 / 106$ & $1-144$ & 7.80 & 65.75 & 76 & $\|-I I \mid$ & Knee & WOMAC & 144 \\
\hline $\begin{array}{l}\text { Pavelka } \\
2002[24]\end{array}$ & $\begin{array}{l}\mathrm{G}(1500 \mathrm{mg}) / \\
\text { placebo }\end{array}$ & $101 / 101$ & $1-144$ & 10.55 & 62.35 & 79 & $\|-\|$ & Knee & WOMAC & 144 \\
\hline $\begin{array}{l}\text { Braham } \\
2003 \text { [25] }\end{array}$ & $\begin{array}{l}\mathrm{G}(1500 \mathrm{mg}) / \\
\text { placebo }\end{array}$ & $24 / 22$ & $1-12$ & 12.98 & 42.65 & 28 & $|-|||$ & Knee & KPS & 12 \\
\hline $\begin{array}{l}\text { McAlinton } \\
2004[26]\end{array}$ & $\begin{array}{l}\mathrm{G}(1500 \mathrm{mg}) / \\
\text { placebo }\end{array}$ & $101 / 104$ & $1-12$ & NA & $>65.00$ & 64 & NA & Knee & WOMAC & 12 \\
\hline $\begin{array}{l}\text { Cibere } \\
2004[27]\end{array}$ & $\begin{array}{l}\mathrm{G}(1500 \mathrm{mg}) / \\
\text { placebo }\end{array}$ & $71 / 66$ & $1-24$ & 1.60 & 64.48 & 56 & $\geq 2$ & Knee & WOMAC & 24 \\
\hline Usha & $\begin{array}{l}\mathrm{G}(1500 \mathrm{mg}) / \\
\text { placebo }\end{array}$ & $30 / 28$ & $1-12$ & 3.05 & 51.03 & NA & $|-|||$ & Knee & VAS & 12 \\
\hline \multicolumn{11}{|l|}{2004 [28] } \\
\hline $\begin{array}{l}\text { Clegg } \\
2006[29]\end{array}$ & $\begin{array}{l}\mathrm{G}(1500 \mathrm{mg}) / \\
\text { placebo }\end{array}$ & $317 / 313$ & $1-24$ & 9.95 & 58.40 & 63 & $\|-I I I$ & Knee & WOMAC & 24 \\
\hline $\begin{array}{l}\text { Herrero-Beaumont } \\
2007 \text { [30] }\end{array}$ & $\begin{array}{l}\mathrm{G}(1500 \mathrm{mg}) / \\
\text { placebo }\end{array}$ & $106 / 104$ & $1-12$ & 7.30 & 63.94 & 93 & $\|-\|$ & Knee & WOMAC & 24 \\
\hline $\begin{array}{l}\text { Rozendaal } \\
2008 \text { [31] }\end{array}$ & $\begin{array}{l}\mathrm{G}(1500 \mathrm{mg}) / \\
\text { placebo }\end{array}$ & $111 / 111$ & $1-12$ & 11.70 & 63.40 & 69 & $>2$ & Hip & WOMAC & 96 \\
\hline $\begin{array}{l}\text { Giordano } \\
2009[32]\end{array}$ & $\begin{array}{l}\mathrm{G}(1500 \mathrm{mg}) / \\
\text { placebo }\end{array}$ & $30 / 30$ & $1-12$ & 6.30 & 57.65 & 70 & $|-|||$ & Knee & WOMAC & 24 \\
\hline Fransen 2014 [33] & $\begin{array}{l}\mathrm{G}(1500 \mathrm{mg}) / \\
\text { placebo }\end{array}$ & 152/151 & $1-48$ & $>2.00$ & 60.90 & 83 & NA & Knee & WOMAC & 96 \\
\hline Kwoh 2014 [34] & $\begin{array}{l}\mathrm{G}(1501 \mathrm{mg}) / \\
\text { placebo }\end{array}$ & $98 / 103$ & $1-12$ & NA & 52.23 & 49 & $0-4$ & Knee & WOMAC & 24 \\
\hline \multicolumn{11}{|l|}{ Chondroitin vs Placebo } \\
\hline Bucsi 1998 [35] & $\begin{array}{l}\text { C(1200 mg)/ } \\
\text { placebo }\end{array}$ & $39 / 46$ & $1-12$ & $>0.50$ & 59.95 & 60 & $|-|||$ & Knee & VAS & 24 \\
\hline $\begin{array}{l}\text { Bourgeois } \\
1998[36]\end{array}$ & $\begin{array}{l}\text { C(1200 mg }) / \\
\text { placebo }\end{array}$ & $83 / 44$ & $1-13$ & NA & 63.35 & 76 & $|-|||$ & Knee & VAS & 13 \\
\hline $\begin{array}{l}\text { Uebelhart } \\
1998[37]\end{array}$ & $\begin{array}{l}\text { C(1200 mg)/ } \\
\text { placebo }\end{array}$ & $23 / 23$ & $1-48$ & NA & 58.50 & 52 & $|-|||$ & Knee & VAS & 48 \\
\hline $\begin{array}{l}\text { Mazieres } \\
2001[38]\end{array}$ & $\begin{array}{l}\text { C(1200 mg)/ } \\
\text { placebo }\end{array}$ & $63 / 67$ & $1-12$ & NA & 67.09 & 75 & $\|-\| \mid$ & Knee & Pain at rest & 12 \\
\hline $\begin{array}{l}\text { Uebelhart } \\
2004 \text { [39] }\end{array}$ & $\begin{array}{l}\text { C(1200 mg)/ } \\
\text { placebo }\end{array}$ & $54 / 56$ & $1-12$ & NA & 63.45 & 81 & $|-|||$ & Knee & $\begin{array}{l}\text { Husskisson visual } \\
\text { analogue score } \\
\text { for pain }\end{array}$ & 12 \\
\hline Michel 2005 [40] & $\begin{array}{l}\text { C(1200 mg }) / \\
\text { placebo }\end{array}$ & $150 / 150$ & $1-96$ & NA & 62.80 & 51 & $|-|||$ & Knee & WOMAC & 96 \\
\hline Clegg 2006 [29] & $\begin{array}{l}\text { C(1200 mg)/ } \\
\text { placebo }\end{array}$ & $318 / 313$ & $1-24$ & 9.60 & 58.20 & 64 & $\|-I\|$ & Knee & WOMAC & 24 \\
\hline $\begin{array}{l}\text { Mazieres } \\
2006[41]\end{array}$ & $\begin{array}{l}\text { C(1200 mg)/ } \\
\text { placebo }\end{array}$ & $153 / 154$ & $1-24$ & 6.40 & 66.00 & 70 & $\|-\|||$ & Knee & Pain at rest & 24 \\
\hline Kahan 2009 [42] & $\begin{array}{l}\text { C(1200 mg)/ } \\
\text { placebo }\end{array}$ & $309 / 313$ & $1-12$ & 6.30 & 62.30 & 68 & $|-|||$ & $\begin{array}{l}\text { Knee/ } \\
\text { hip }\end{array}$ & WOMAC & 12 \\
\hline Wildi 2011 [43] & $\begin{array}{l}\text { C(800 mg }) / \\
\text { placebo }\end{array}$ & $35 / 34$ & $1-48$ & $>0.50$ & 62.26 & 59 & $|-|||$ & Knee & WOMAC & 48 \\
\hline
\end{tabular}


Table 1 Characteristics of the included studies for osteoarthritis of knee and/or hip (Continued)

\begin{tabular}{|c|c|c|c|c|c|c|c|c|c|c|}
\hline Study, year & $\begin{array}{l}\text { Treatment } \\
\text { (daily dose) }\end{array}$ & $\begin{array}{l}\text { Participants } \\
\text { randomized (n) }\end{array}$ & $\begin{array}{l}\text { Treatment } \\
\text { duration } \\
\text { (weeks) }\end{array}$ & $\begin{array}{l}\text { Symptom } \\
\text { duration (year) }\end{array}$ & $\begin{array}{l}\text { Mean } \\
\text { age (year) }\end{array}$ & $\begin{array}{l}\text { Female } \\
(\%)\end{array}$ & $\begin{array}{l}\text { OA } \\
\text { grade }\end{array}$ & Joint & $\begin{array}{l}\text { Pain outcome } \\
\text { extracted }\end{array}$ & $\begin{array}{l}\text { Timepoint } \\
\text { extracted } \\
\text { (weeks) }\end{array}$ \\
\hline Zegels 2013 [7] & $\begin{array}{l}\text { C(1200 mg)/ } \\
\text { placebo }\end{array}$ & $236 / 117$ & $1-12$ & NA & 65.17 & 65 & NA & Knee & Global pain & 12 \\
\hline Fransen 2014 [33] & $\begin{array}{l}\mathrm{C}(800 \mathrm{mg}) / \\
\text { placebo }\end{array}$ & $151 / 151$ & $1-48$ & $>2.00$ & 60.05 & 83 & NA & Knee & WOMAC & 96 \\
\hline \multicolumn{11}{|c|}{ Glucosamine + Chondroitin vs Placebo } \\
\hline Clegg 2006 [29] & $\begin{array}{l}\mathrm{G}+\mathrm{C}(1500+ \\
1200 \mathrm{mg}) / \\
\text { placebo }\end{array}$ & $317 / 313$ & $1-24$ & 9.80 & 58.40 & 63 & $\|-1\|$ & Knee & WOMAC & 24 \\
\hline Fransen 2014 [33] & $\begin{array}{l}\mathrm{G}+\mathrm{C}(1500+ \\
800 \mathrm{mg}) / \\
\text { placebo }\end{array}$ & $151 / 151$ & $1-48$ & $>2.00$ & 60.65 & 85 & NA & Knee & WOMAC & 96 \\
\hline Lugo 2016 [44] & $\begin{array}{l}\mathrm{G}+\mathrm{C}(1500+ \\
1200 \mathrm{mg}) / \\
\text { placebo }\end{array}$ & $65 / 58$ & $1-12$ & NA & 52.84 & 54 & $\|-1\|$ & Knee & WOMAC & 24 \\
\hline $\begin{array}{l}\text { Roman-Blas } \\
2017 \text { [11] }\end{array}$ & $\begin{array}{l}\mathrm{G}+\mathrm{C}(1500+ \\
1200 \mathrm{mg}) / \\
\text { placebo }\end{array}$ & $80 / 78$ & $1-24$ & 6.20 & 65.99 & 84 & $\|-1\|$ & Knee & Global pain & 24 \\
\hline
\end{tabular}

G glucosamine, C chondroitin, G + C glucosamine + chondroitin, NA not available, WOMAC Western Ontario and McMaster Universities, KPS Knee Pain Scale, VAS Visual Analogue Scale

In general, the summary of DMOADs had a better effect compared with placebo. The overall effect size was -0.090 (95\% CI, -0.242 to 0.061$)$. After being transformed, the effect size for the subgroup of chondroitin versus placebo was -0.462 units $(95 \% \mathrm{CI},-0.752$ to - 0.170 units). Meanwhile, other comparisons presented no significant effect.

\section{Stiffness}

Thirteen trials (4079 patients) contributed to the outcome of stiffness. The overall difference in stiffness improvement versus placebo was -0.142 (95\% CI, -0.301 to 0.017 ) for the summary of these treatments, -0.305
(95\% CI, -0.609 to 0.002$)$ for glucosamine, $0.026(95 \%$ $\mathrm{CI},-0.073$ to 0.126$)$ for chondroitin and -0.070 (95\% $\mathrm{CI},-0.214$ to 0.074 ) for the combination of glucosamine and chondroitin (Table 2). In terms of stiffness, only glucosamine showed statistical significance when compared with placebo.

\section{Safety}

Twenty studies reported the withdrawals of patients due to AEs. Eight studies reported the number of patients with AEs such as diarrhea, abdominal pain, nausea, headache, and others. Figure 1 showed the results of safety and tolerability including the number of withdrawals due to AEs.

Table 2 Effect sizes of symptomatic outcomes

\begin{tabular}{|c|c|c|c|c|c|c|c|c|}
\hline \multirow[t]{2}{*}{ Outcomes } & \multirow[t]{2}{*}{ Interventions } & \multirow{2}{*}{$\begin{array}{l}\text { No. of } \\
\text { studies }\end{array}$} & \multicolumn{3}{|c|}{ Test of association } & \multicolumn{3}{|c|}{ Test of heterogeneity } \\
\hline & & & $\mathrm{SMD}$ & $95 \% \mathrm{Cl}$ & $P$ value & Model & $P^{2}(\%)$ & $P$ value \\
\hline \multirow[t]{4}{*}{ Pain } & G vs. PBO & 14 & -0.105 & $(-0.254,0.045)$ & 0.170 & Random & 72.50 & 0.000 \\
\hline & C vs. PBO & 12 & -0.216 & $(-0.360,-0.071)$ & 0.003 & Random & 70.80 & 0.000 \\
\hline & $G+C$ vs. $P B O$ & 4 & 0.792 & $(-0.296,1.880)$ & 0.153 & Random & 98.50 & 0.000 \\
\hline & Overall & 30 & -0.071 & $(-0.228,0.085)$ & 0.369 & Random & 90.10 & 0.000 \\
\hline \multirow[t]{4}{*}{ Function } & G vs. PBO & 11 & -0.126 & $(-0.264,0.012)$ & 0.073 & Random & 64.10 & 0.002 \\
\hline & C vs. PBO & 10 & -0.220 & $(-0.358,-0.081)$ & 0.002 & Random & 68.30 & 0.001 \\
\hline & $G+C$ vs. $P B O$ & 4 & 0.556 & $(-0.368,1.480)$ & 0.238 & Random & 98.00 & 0.000 \\
\hline & Overall & 25 & -0.090 & $(-0.242,0.061)$ & 0.242 & Random & 89.00 & 0.000 \\
\hline \multirow[t]{4}{*}{ Stiffness } & G vs. PBO & 8 & -0.305 & $(-0.609,-0.002)$ & 0.048 & Random & 89.00 & 0.000 \\
\hline & C vs. PBO & 3 & 0.026 & $(-0.073,0.126)$ & 0.604 & Fixed & 31.70 & 0.232 \\
\hline & $G+C$ vs. $P B O$ & 2 & -0.070 & $(-0.214,0.074)$ & 0.340 & Fixed & 0.00 & 0.582 \\
\hline & Overall & 13 & -0.142 & $(-0.301,0.017)$ & 0.081 & Random & 82.90 & 0.000 \\
\hline
\end{tabular}




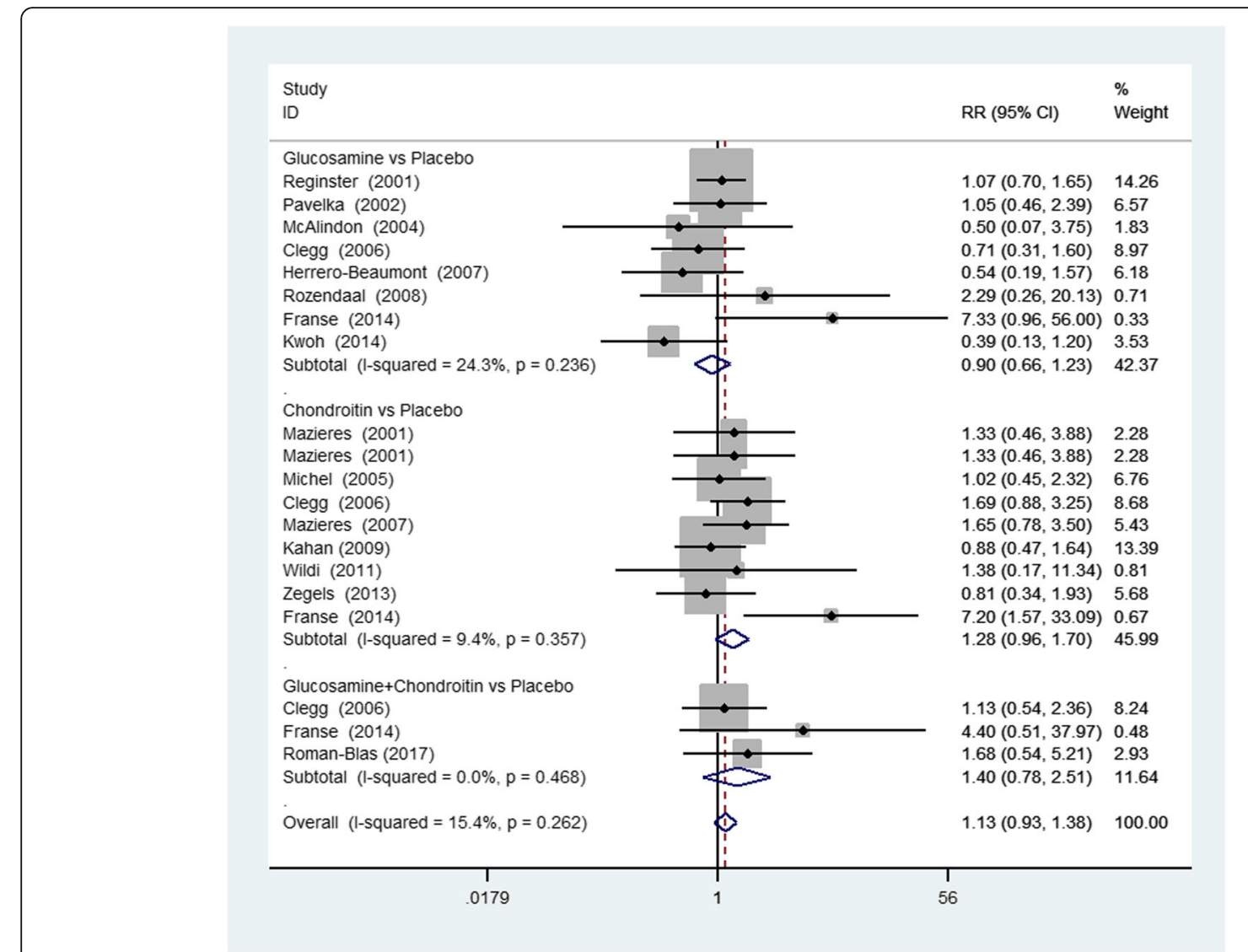

Fig. 1 Forest plot of RR and 95\% Cls of studies of adverse events. RR relative risk, 95\% Cl confidence interval, G + C glucosamine + chondroitin

There was no significant difference in the comparison between any options versus placebo. In addition, six specific kinds of AEs were also analyzed by meta-analysis, and the results were presented in Table 3. The meta-analysis of those studies showed that there was no statistically significant difference between the group of SYSADOAs and placebo group.

\section{Sensitivity analysis}

We also conducted sensitivity analyses for those outcomes to confirm the robustness of the results. Sensitivity analysis of sample size and methodological quality of included studies did not show any major change in view of pain, function, and stiffness (Additional file 1: Table S1).

\section{Discussion}

In this study, we performed four individual outcome-oriented meta-analyses of randomized control trials selected on the basis of their high methodologic quality, assessing the effectiveness and safety of glucosamine, chondroitin, and the combination for the treatment of knee and/or hip OA. In our meta-analysis, the pooled effect sizes suggested that these SYSADOAs showed no significant effect on the outcome of pain, function, and stiffness compared with placebo. However, the estimates between chondroitin and placebo showed that chondroitin could alleviate pain symptoms and improve function. Compared with placebo, glucosamine proved significant effect only on the sapect of stiffness improvement. Whereas, in this

Table 3 Risk ratio (95\% Cl) of specific adverse effects between different treatment groups

\begin{tabular}{llllllll}
\hline Comparison & Gl AE & CV AE & CNS AE & MU AE & Infection & Skin AE & Others \\
\hline G vs PBO & $0.99(0.79,1.23)$ & NA & $0.72(0.46,1.10)$ & $1.52(0.88,2.63)$ & $1.07(0.50,2.32)$ & $0.80(0.38,1.68)$ & $1.21(0.98,1.48)$ \\
C vs PBO & $0.35(0.14,0.87)$ & $1.13(0.45,2.84)$ & $0.79(0.37,1.67)$ & NA & $0.98(0.72,1.34)$ & $1.00(0.41,2.45)$ & NA \\
G + C vs PBO & $2.79(0.30,26.00)$ & NA & $1.86(0.36,9.74)$ & $2.79(0.30,26.00)$ & $2.79(0.12,67.10)$ & NA & $4.66(0.23,94.79)$ \\
Overall & $0.92(0.74,1.13)$ & $1.13(0.45,2.84)$ & $0.77(0.54,1.11)$ & $1.58(0.93,2.70)$ & $1.01(0.76,1.35)$ & $0.88(0.50,1.55)$ & $1.22(1.00,1.50)$ \\
\hline
\end{tabular}

G glucosamine, $C$ chondroitin, $G+C$ glucosamine + chondroitin, PBO placebo, NA not available, Gl gastrointestinal, CV cardiovascular, CNS central nervous system, MU musculoskeletal 
head-to-head meta-analysis, the combination of glucosamine and chondroitin did not have enough evidence to be superior to placebo. There was no significant difference in the incidence of AEs and discontinuations of AEs for these SYSADOAs when compared with placebo.

Glucosamine and chondroitin are dietary supplements commonly used by those OA patents and are recommended by physician for purported analgesic and chondroprotective effects [45]. Glucosamine was considered as a water-soluble amino monosaccharide, which was one of the most abundant monosaccharides in the human body and is in high quantities in articular cartilage. Chondroitin was a major component of the extracellular matrix of articular cartilage, which played an important role in creating considerable osmotic pressure. In this way, it could provide cartilage with resistance and elasticity to resist tensile stresses during loading condition [46]. Chondroitin and glucosamine were tested in several clinical trials of osteoarthritis. In spite of the controversy surrounding the SYSADOAs, they were commonly used to control symptoms of OA in western countries. Therefore, an understanding of chondroitin and glucosamine consumption is of significance for public health.

In the previous meta-analysis, Richy and colleagues combined 7 trials of glucosamine and 8 trials of chondroitin for osteoarthritis treatment demonstrated comparable efficacies of chondroitin and glucosamine and a highly significant effectiveness of glucosamine on all involved outcomes when compared with placebo, which was contrary with our results of glucosamine and the combination therapy [47]. Collectively, their study showed that chondroitin was considered effective on pain relief, which was consistent with our finding. Additionally, a pair-wise meta-analysis of chondroitin by Monfort and colleagues suggested that chondroitin present a slight to moderate efficacy in the symptomatic treatment of OA, with an excellent safety profile [48]. The subgroup of our study covering 12 RCTs of chondroitin present that chondroitin showed significant effect in both outcome of pain and function improvement. In our study, only 4 RCTs met the criteria of combination therapy and were included in the subgroup of this meta-analysis. And glucosamine and chondroitin combination therapy failed to reduce joint pain and function improvement; this may due to original data restraints. However, this finding was similar to a least RCT publish in 2017. Roman-Blas and his colleagues indicated that chondroitin and glucosamine combination therapy failed to reduce joint pain [11]. But in the subgroup of patients with moderate-to-severe knee pain of their RCT, significant relief of joint pain with this combination therapy was observed.

Considering the reasons above, we do not oppose the use of chondroitin, although chondroitin were not recommended according to Osteoarthritis Research Society
International (OARSI) guidelines published in 2014. In fact, we recommend that the future guidelines would reconsider the oral treatment option of chondroitin for the treatment of $\mathrm{OA}$ in the clinical feature. In terms of the aspect of safety, the current study provides valuable information to help physicians make treatment decisions for OA patients.

It was worth mentioning that a comprehensive and rigorous literature search strategy was performed in our meta-analysis, which insured that it was unlikely to miss other relevant trials. All the methods were strict inclusion and exclusion criteria to demonstrate the effectiveness and significance of our conclusions. In our meta-analysis, dosage was strictly restricted and the RCTs included should met these criteria, so the results could be comparable and reasonable. To minimize bias, studies selection, quality assessment, and data extraction were completed by two reviewers independently. What is more, several sensitivity analyses of low quality were conducted to make the results more sensible and comprehensive.

There are several limitations in this meta-analysis that need to be considered. Firstly, the quality of original data resulted in some limitation of the quality of our analysis. Secondly, in this study, there is potential publication bias. Some unpublished papers and abstracts were not taken into consideration because of unavailable data. The language might also introduce a bias. Actually, we selected only the English language. Thirdly, several specific adverse effects of interventions cannot be proven due to the inadequate reporting of adverse event data. Moreover, the numbers of RCTs between combination therapy of glucosamine and chondroitin were limited. Researches on SYSADOAs are still required due to the limitations on the quality and quantity of the available evidence.

\section{Conclusion}

In conclusion, in accordance with our results, it can be definitively stated that oral chondroitin in recommended dosage is more effective than placebo on relieving pain and improving physical function. Compared with placebo, glucosamine showed significant effect on the outcome of stiffness. In the aspect of safety, both compounds are well tolerated. Actually, combination therapy is definitely common in clinical practice, and treatment intervention on $\mathrm{OA}$ patients like the combination of SYSADOAs was also usual in clinical experience. Our study would help highlight the potential role of SYSADOAs. Further studies of the glucosamine and chondroitin combination therapy need to explore the effectiveness for an accurate characterization of osteoarthritis treatment and their possible mechanism. Therefore, the above information, along with the safety profile should be conducive to clinicians in decision making. 


\section{Additional file}

Additional file 1: Table S1. The results of sensitivity analysis. Figure S1. Summary of study search and selection. RCT randomized controlled trail. Figure S2. Plots of bias risk. Figure S3. Funnel plot of effect size. (DOCX 4698 kb)

\section{Abbreviations}

AEs: Adverse effects; DMOADs: Disease-modifying OA drugs; NSAIDs: Nonsteroidal anti-inflammatory drugs; OA: Osteoarthritis; OARSI: Osteoarthritis Research Society International; RR: Relative risk; SYSADOAs: Symptomatic slow-acting drugs

\section{Funding}

This study was supported by the Research Innovation Program for College Graduates of Jiangsu Province (YKC16019) and Jiangsu Students' Platform for Innovation and Entrepreneurship Training Program (201710304058).

\section{Authors' contributions}

All authors certified that they have participated in the conceptual design of this work, the analysis of the data, and the writing of the manuscript to take public responsibility for it. XZ drafted the protocol and wrote the final paper. $\mathrm{LJ}$ contributed to the research design and made critical revisions. LS and DW participated in data collection. JR participated in the data analysis. All authors reviewed the final version of the manuscript and approve it for publication.

\section{Ethics approval and consent to participate}

Not applicable

\section{Consent for publication}

Written informed consent was obtained from all patients for data publication, including images.

\section{Competing interests}

The authors declare that they have no competing interests.

\section{Publisher's Note}

Springer Nature remains neutral with regard to jurisdictional claims in published maps and institutional affiliations.

\section{Author details}

'Baoshan Center for Disease Control and Prevention, Shanghai, People's Republic of China. ${ }^{2}$ Department of Epidemiology, School of Public Health, Nantong University, Nantong, Jiangsu Province, People's Republic of China. ${ }^{3}$ Department of Orthopedics Surgery, The Second Affiliated Hospital of Harbin Medical University, Harbin, Heilongjiang Province, People's Republic of China. ${ }^{4}$ Shanghai Key Laboratory for Molecular Imaging, Shanghai University of Medicine \& Health Sciences, Shanghai, People's Republic of China.

Received: 8 January 2018 Accepted: 25 June 2018

Published online: 06 July 2018

\section{References}

1. Glyn-Jones S, Palmer AJ, Agricola R, et al. Osteoarthritis. Lancet. 2015; 386(9991):376-87

2. Lotz M, Martel-Pelletier J, Christiansen C, et al. Value of biomarkers in osteoarthritis: current status and perspectives. Ann Rheum Dis. 2013;72(11) 1756-63.

3. Felson DT, Zhang Y. An update on the epidemiology of knee and hip osteoarthritis with a view to prevention. Arthritis Rheum. 1998;41(8):1343-55

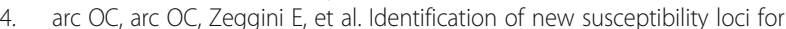
osteoarthritis (arcOGEN): a genome-wide association study. Lancet. 2012; 380(9844):815-23.

5. Nuesch E, Dieppe P, Reichenbach S, Williams S, Iff S, Juni P. All cause and disease specific mortality in patients with knee or hip osteoarthritis: population based cohort study. Bmj. 2011;342:d1165.
6. Essex MN, O'Connell MA, Behar R, Bao W. Efficacy and safety of nonsteroidal anti-inflammatory drugs in Asian patients with knee osteoarthritis: summary of a randomized, placebo-controlled study. Int J Rheum Dis. 2016;19(3):262-70.

7. Zegels B, Crozes $P$, Uebelhart D, Bruyere $O$, Reginster JY. Equivalence of a single dose (1200 mg) compared to a three-time a day dose $(400 \mathrm{mg})$ of chondroitin $4 \& 6$ sulfate in patients with knee osteoarthritis. Results of a randomized double blind placebo controlled study. Osteoarthr Cartil. 2013;21(1):22-7.

8. Persiani S, Rotini R, Trisolino G, et al. Synovial and plasma glucosamine concentrations in osteoarthritic patients following oral crystalline glucosamine sulphate at therapeutic dose. Osteoarthr Cartil. 2007;15(7):764-72.

9. Conte A, Volpi N, Palmieri L, Bahous I, Ronca G. Biochemical and pharmacokinetic aspects of oral treatment with chondroitin sulfate. Arzneimittelforschung. 1995:45(8):918-25.

10. Verbruggen G, Goemaere S, Veys EM. Chondroitin sulfate: S/DMOAD (structure/disease modifying anti-osteoarthritis drug) in the treatment of finger joint OA. Osteoarthr Cartil. 1998;6 Suppl A:37-8.

11. Roman-Blas JA, Castañeda S, Sánchez-Pernaute O, Largo R, HerreroBeaumont G. Combined treatment with chondroitin sulfate and glucosamine sulfate shows no superiority over placebo for reduction of joint pain and functional impairment in patients with knee osteoarthritis: a six-month multicenter, randomized, double-blind, Placebo-Controlled Clinical Trial. Arthritis Rheumatol. 2017;69(1):77-85

12. McAlindon TE, Bannuru RR, Sullivan MC, et al. OARSI guidelines for the nonsurgical management of knee osteoarthritis. Osteoarthr Cartil. 2014;22(3):363-88.

13. Panic N, Leoncini E, Belvis $G$ D, et al. Evaluation of the endorsement of the Preferred Reporting Items for Systematic reviews and Meta-Analysis (PRISMA) statement on the quality of published systematic review and meta-analyses[J]. Plos One. 2013;8(12):e83138.

14. European Medicines Agency. EMEA public statement on the suspension of the marketing authorisation for Bextra (valdecoxib) in the European Union [online]. (2005) Available at: http://www.ema.europa.eu/docs/en_GB/ document library/Public statement/2009/12/WC500018391.pdf.

15. Green JPTHaS. Corchrane Reviewers' Handbook 5.1.0. Review Manage 2011.

16. Juni P, Reichenbach S, Dieppe P. Osteoarthritis: rational approach to treating the individual. Best Pract Res Clin Rheumatol. 2006;20(4):721-40.

17. Juhl C, Lund H, Roos EM, Zhang W, Christensen R. A hierarchy of patientreported outcomes for meta-analysis of knee osteoarthritis trials: empirical evidence from a survey of high impact journals. Arthritis. 2012;2012:136245.

18. Cooper HM, Hedges LV. The handbook of research synthesis. New York: Russell Sage Foundation; 1994

19. Cooper HM, Hedges LV, Valentine JC. The handbook of research synthesis and meta-analysis. 2nd ed. New York: Russell Sage Foundation; 2009.

20. Bannuru RR, Schmid CH, Kent DM, Vaysbrot EE, Wong JB, McAlindon TE. Comparative effectiveness of pharmacologic interventions for knee osteoarthritis: a systematic review and network meta-analysis. Ann Intern Med. 2015;162(1):46-54.

21. Noack W, Fischer M, Forster KK, Rovati LC, Setnikar I. Glucosamine sulfate in osteoarthritis of the knee. Osteoarthr Cartil. 1994;2(1):51-9.

22. Houpt JB, McMillan R, Wein C, Paget-Dellio SD. Effect of glucosamine hydrochloride in the treatment of pain of osteoarthritis of the knee. J Rheumatol. 1999;26(11):2423-30.

23. Reginster JY, Deroisy R, Rovati LC, et al. Long-term effects of glucosamine sulphate on osteoarthritis progression: a randomised, placebo-controlled clinical trial. Lancet. 2001;357(9252):251-6.

24. Pavelká K, Gatterová J, Olejarová M, Machacek S, Giacovelli G, Rovati LC. Glucosamine sulfate use and delay of progression of knee osteoarthritis: a 3-year, randomized, placebo-controlled, double-blind study. Arch Intern Med. 2002;162(18):2113-23.

25. Braham R, Dawson B, Goodman C. The effect of glucosamine supplementation on people experiencing regular knee pain. $\mathrm{Br} J$ Sports Med. 2003;37(1):45.

26. McAlindon T, Formica M, LaValley M, Lehmer M, Kabbara K. Effectiveness of glucosamine for symptoms of knee osteoarthritis: results from an internet-based randomized double-blind controlled trial. Am J Med. 2004;117(9):643-9.

27. Cibere J, Kopec JA, Thorne A, et al. Randomized, double-blind, placebocontrolled glucosamine discontinuation trial in knee osteoarthritis. Arthritis Rheum. 2004:51(5):738-45.

28. Usha PR, Naidu MU. Randomised, double-blind, parallel, placebo-controlled study of oral glucosamine, methylsulfonylmethane and their combination in osteoarthritis. Clin Drug Investig. 2004;24(6):353-63. 
29. Clegg DO, Reda DJ, Harris CL, et al. Glucosamine, chondroitin sulfate, and the two in combination for painful knee osteoarthritis. N Engl J Med. 2006; 354(8):795-808.

30. Herrero-Beaumont G, Ivorra JA, Del Carmen Trabado M, et al. Glucosamine sulfate in the treatment of knee osteoarthritis symptoms: a randomized, double-blind, placebo-controlled study using acetaminophen as a side comparator. Arthritis Rheum. 2007;56(2):555-67.

31. Rozendaal RM, Koes BW, van Osch GJ, et al. Effect of glucosamine sulfate on hip osteoarthritis: a randomized trial. Ann Intern Med. 2008;148(4):268-77.

32. Giordano N, Fioravanti A, Papakostas P, Montella A, Giorgi G, Nuti R. The efficacy and tolerability of glucosamine sulfate in the treatment of knee osteoarthritis: a randomized, double-blind, placebo-controlled trial. Curr Ther Res. 2009;70(3):185-96.

33. Fransen M, Agaliotis M, Nairn L, et al. Glucosamine and chondroitin for knee osteoarthritis: a double-blind randomised placebo-controlled clinical trial evaluating single and combination regimens. Ann Rheum Dis. 2015;74(5):851-8.

34. Kwoh CK, Roemer FW, Hannon MJ, et al. Effect of oral glucosamine on joint structure in individuals with chronic knee pain: a randomized, placebocontrolled clinical trial. Arthritis Rheum. 2014;66(4):930-9.

35. Bucsi L, Poór G. Efficacy and tolerability of oral chondroitin sulfate as a symptomatic slow-acting drug for osteoarthritis (SYSADOA) in the treatment of knee osteoarthritis. Osteoarthr Cartil. 1998;6 Suppl A(5):31-6.

36. Bourgeois P, Chales G, Dehais J, Delcambre B, Kuntz JL, Rozenberg S. Efficacy and tolerability of chondroitin sulfate $1200 \mathrm{mg} /$ day vs chondroitin sulfate $3 \times 400$ mg/day vs placebo. Osteoarthr Cartil. 1998;6(Suppl A):25-30.

37. Uebelhart $D$, Thonar EJ, Delmas PD, Chantraine A, Vignon E. Effects of oral chondroitin sulfate on the progression of knee osteoarthritis: a pilot study. Osteoarthr Cartil. 1998;6 Suppl A(21):39-46.

38. Mazieres B, Combe B, Van AP, Tondut J, Grynfeltt M. Chondroitin sulfate in osteoarthritis of the knee: a prospective, double blind, placebo controlled multicenter clinical study. J Rheumatol. 2001;28(1):173-81.

39. Uebelhart $D$, Malaise $M$, Marcolongo $R$, et al. Intermittent treatment of knee osteoarthritis with oral chondroitin sulfate: a one-year, randomized, doubleblind, multicenter study versus placebo. Osteoarthr Cartil. 2004;12(4):269-76.

40. Michel BA, Stucki G, Frey D, et al. Chondroitins 4 and 6 sulfate in osteoarthritis of the knee: a randomized, controlled trial. Arthritis Rheum. 2005:52(3):779-86

41. Mazieres B, Hucher M, Zaim M, Garnero P. Effect of chondroitin sulphate in symptomatic knee osteoarthritis: a multicentre, randomised, double-blind, placebo-controlled study. Ann Rheum Dis. 2007;66(5):639-45.

42. Kahan A, Uebelhart D, De VF, Delmas PD, Reginster JY. Long-term effects of chondroitins 4 and 6 sulfate on knee osteoarthritis: the study on osteoarthritis progression prevention, a two-year, randomized, double-blind, placebo-controlled trial. Arthritis Rheum. 2009;60(2):524-33.

43. Wildi LM, Raynauld JP, Martelpelletier J, et al. Chondroitin sulphate reduces both cartilage volume loss and bone marrow lesions in knee osteoarthritis patients starting as early as 6 months after initiation of therapy: a randomised, double-blind, placebo-controlled pilot study using MRI. Ann Rheum Dis. 2011;70(6):982-9.

44. Lugo JP, Saiyed ZM, Lane NE. Efficacy and tolerability of an undenatured type II collagen supplement in modulating knee osteoarthritis symptoms: a multicenter randomized, double-blind, placebo-controlled study. Nutr J. 2016;15:14.

45. DiNubile NA. Glucosamine and chondroitin sulfate in the management of osteoarthritis. Commentary Postgrad Med 2009;121(4):48-50.

46. Jomphe C, Gabriac M, Hale TM, et al. Chondroitin sulfate inhibits the nuclear translocation of nuclear factor-kappaB in interleukin-1 betastimulated chondrocytes. Basic Clin Pharmacol Toxicol. 2008;102(1):59-65.

47. Richy F, Bruyere O, Ethgen O, Cucherat M, Henrotin Y, Reginster JY. Structural and symptomatic efficacy of glucosamine and chondroitin in knee osteoarthritis: a comprehensive meta-analysis. Arch Intern Med. 2003; 163(13):1514-22

48. Monfort J, Martel-Pelletier J, Pelletier J-P. Chondroitin sulphate for symptomatic osteoarthritis: critical appraisal of meta-analyses. Curr Med Res Opin. 2008:24(5):1303-8.

\section{Ready to submit your research? Choose BMC and benefit from:}

- fast, convenient online submission

- thorough peer review by experienced researchers in your field

- rapid publication on acceptance

- support for research data, including large and complex data types

- gold Open Access which fosters wider collaboration and increased citations

- maximum visibility for your research: over $100 \mathrm{M}$ website views per year

At BMC, research is always in progress.

Learn more biomedcentral.com/submissions 